\title{
Unilateral versus bilateral pedicle screw fixation with oblique lateral interbody fusion in the treatment of multi-level degenerative lumbar disease: a prospective study
}

\section{Zecheng Cai}

Ningxia Medical University

Jianqun Zhang

Ningxia Medical University General Hospital

Shulong Yang

Ningxia Medical University

Xiaoyin Liu

Ningxia Medical University General Hospital

\section{Zhen Chen}

Ningxia Medical University General Hospital

\section{Rong Ma}

Ningxia Medical University General Hospital

Simin Liang

Ningxia Medical University General Hospital

Xiaoli Ding

Ningxia Medical University General Hospital

\section{Zongjun Ma}

Ningxia Medical University General Hospital

\section{Peng Wu}

Ningxia Medical University General Hospital

Zhaohui Ge ( $\nabla$ myovid@126.com )

Ningxia Medical University General Hospital

\section{Research Article}

Keywords: Unilateral pedicle screw, multi-level degenerative lumbar disease, oblique lumbar interbody fusion

Posted Date: February 16th, 2021 
DOl: https://doi.org/10.21203/rs.3.rs-199271/v1

License: (c) (1) This work is licensed under a Creative Commons Attribution 4.0 International License. Read Full License 


\section{Abstract}

Background: The purpose of this study was to compare the clinical and radiological outcomes of oblique lateral interbody fusion (OLIF) combined with unilateral (UPSF) and bilateral pedicle screw fixation (BPSF) in the treatment of multi-level degenerative lumbar disease (LDD).

Methods: We conducted a prospective study from May 2016 to June 2018. A total of 81 LDD patients were randomized into groups. The first group involving 39 patients received OLIF combined with USPF (UPS group), and the second group of 41 patients received OLIF combined with BPSF (BPS group). The perioperative conditions included intraoperative bleeding, operating time, average hospital stay, and hospitalization expenses. The clinical outcomes included Visual Analogue Scale (VAS), Oswestry Disability Index (ODI), and complications. Moreover, the radiological outcomes included disc height, fusion rate, and cage subsidence rate. These perioperative conditions, clinical outcomes, and radiological conditions of the two study groups were evaluated and compared. All the patients were followed up for 24 to 28 months, with an average follow-up time of 26 months.

Results: The intraoperative bleeding, operating time, and hospitalization expenses of the UPS group were significantly less compared with those of the BPS group. Compared with preoperatively, the VAS and ODI scores of the two groups were improved significantly after the operation. At 6 months after operation, the VAS score for back pain and ODI of the UPS group were better than in the BPS group $(P<0.05)$. Both groups were able to maintain the intervertebral space height of the fusion segment, and there was no significant difference in the fusion rate at the 24 months. There were no significant differences in complications. At the 24 months, there was no significant difference in the cage subsidence of the fusion segment between the two groups. Finally, there was no loose screw and screw fracture in both groups.

Conclusions: OLIF combined with UPSF is an effective and reliable surgical method for the treatment of multilevel LDD.

\section{Background}

Lumbar interbody fusion has been proven as an effective operation method for the treatment of various LDDs. The classical posterior lumbar interbody fusion, such as PLIF, TLIF, among others, should invade the spinal canal during nerve decompression, which may cause nerve damage [1]. Silvestre et al. first reported OLIF in 2012. The surgical channel is the natural space between the psoas major muscle and the abdominal aorta. The spinal canal is fully protected during decompression and fusion, which maximizes the protection of nerve tissue. Therefore, it has received widespread attention from spine surgeons in recent years [2]. Patients with single-level fusion and mild osteoporosis can receive OLIF stand alone. However, in the face of multi-segment fusion, moderate to severe osteoporosis, and intraoperative endplate damage, it is difficult to maintain the stability of the postoperative spine; therefore, auxiliary posterior pedicle screw fixation is required [3]. In the selection of fixation, BPSF constitutes the standard operative treatment, which has the advantages of high mechanical strength and fusion rate. 
However, long-term follow-up studies have found that BPSF is prone to complications, such as reduced bone mass in the fused segment, and adjacent segment disease [4]. Kabins et al. reported for the first time that UPSF can achieve similar clinical efficacy and fusion rate as BPSF [5]. Yücesoy et al. found that BPSF significantly reduces lumbar range of motion (ROM) compared with UPSF through biomechanical studies [6]. Gu et al. conducted a prospective follow-up of 74 patients and reported that in MIS-TLIF, UPSF has the advantages of short operative time and causes less intraoperative blood loss, and is equivalent to BPSF in clinical efficacy and radiological outcomes [7].

Currently, reports on UPSF and BPSF are mostly focused on TLIF and improved TLIF, while OLIF studies are rare [8]. Wen et al. through a retrospective study documented that OLIF combined with UPSF is similar to BPSF in clinical efficacy. Unfortunately their research focused on single-segment surgery of the lumbar spine [9]. At present, there is no research on multi-level LDD with OLIF combined with different posterior fixation. The previous finite element study of our research group found that the ROM of OLIF combined with UPSF is greater than BPSF, but the peak stress of the screw-rod and cage are far from reaching their yield strength [10]. In view of this, we combined the previous finite element research of our research group to further explore the application and clinical efficacy of OLIF combined with UPSF and BPSF in multilevel LDD.

\section{Materials And Methods}

\section{Study design}

This study was a prospective cohort study and was conducted at the General Hospital of Ningxia Medical University from May 2016 to June 2018. All participants in this study strictly followed the Declaration of Helsinki. The Scientific Research and Ethics Review Committee of the General Hospital of Ningxia Medical University approved this study on April 26, 2019 (NO.2019-038). All participants in this study provided informed consent. The patients were assigned to different groups using the random number table method. The surgical operation was completed by only one doctor (Zhaohui. Ge), and the surgeon remained blinded to the group assignment of the patients before the operation started. Two independent radiologists evaluated the radiologic data, and the final result was the average of the two radiologists evaluations.

\section{Patients}

The inclusion criteria were: (1) the patient must have been over 40 years old; (2) diagnosed with lumbar degenerative diseases, such as degenerative lumbar scoliosis, lumbar spinal stenosis, lumbar disc herniation, lumbar spondylolisthesis (within $\mathbb{\Xi}^{\circ}$ ) and/or lumbar instability; (3) low back pain and/or radicular pain for more than 3 months and conservative treatment was ineffective, which seriously affected normal life; (4) need for multi-level fusion and fixation; (5) and at least 24 months of complete follow-up. The exclusion criteria were: (1) responsible segments that required fusion included L5-S1; (2) severely obese patients (BMI $\geq 35)$; (3) a history of lumbar fusion internal fixation and abdominal surgery. 


\section{Surgical procedure}

After general anesthesia was successful, the patient took the standard right decubitus position, fixed the armpit, pelvis and left lower limb with adhesive tape, and slightly bent the hip and knee. The operative segments were determined using a "C" arm X-ray fluoroscopy machine, and a transverse incision was marked, with a length of about $3-5 \mathrm{~cm}$. After that, disinfection and laying of sterile towel were completed. The skin was cut, as well as the subcutaneous tissue and fascia sequentially, and the external oblique muscle, internal oblique muscle, and transversus abdominis were bluntly separated with a vascular forceps until the retroperitoneal space was reached. With the operator's index finger downward, and touching the internal wall of the iliac bone, the extraperitoneal fat was continued to be separated inward and downward bluntly, then the quadratus lumborum transferred and the extraperitoneal fat and ureter carefully separated forward. The upper and lower soft tissues were dissociated, and the extraperitoneal structures gently pushed forward after penetrating. The gap between psoas major and abdominal aorta was found by the end of index finger. Following the guidance of the index finger, the positioning guide needle was inserted into the anterior and middle $1 / 3$ of the intervertebral space of the surgical segment for fluoroscopy positioning. Step by step, the casing was inserted and the working channel established, followed by the fixing of the cold light source firmly, then the working channel opened appropriately, and then the intervertebral disc bluntly separated and exposed. After resection of the annulus fibrosus, an osteotome was inserted into the intervertebral space and the contralateral annulus fibrosus was punctured. Reamer and curette were used to treat the intervertebral disc tissue, including the cartilage endplate, but the intact bony endplate was retained. Different size cage models were used to expand the intervertebral space to a satisfactory height step by step. After filling the allogeneic bone with the cage (Clydesdale Spinal System, Medtronic, Inc., Minneapolis, MN, USA) of appropriate size, the cage was inserted into the intervertebral space after being fixed with a silk thread to complete the segmental stretching, indirect decompression, and interface fixation.

After decompression and fusion, the patient was changed to a prone position and the surgical area was disinfected. The space between the multifidus muscle and the longissimus muscle (Wiltse approach) was used for unilateral or bilateral pedicle screw fixation (Medtronic, Inc., Minneapolis, MN, USA). Taking UPSF as an example: the "C" arm X-ray fluoroscopy machine located the target segment. The skin and lumbodorsal fascia were cut longitudinally at $2.5 \mathrm{~cm}$ next to the spinous process. The index finger was used to bluntly separate the gap between the multifidus muscle and the longissimus muscle. With the aid of the retractor, the unilateral facet joints were exposed. Weinstein method was used for positioning, a unilateral pedicle screw was implanted, a titanium rod of appropriate length was taken to connect the tail of the pedicle screw, and the tail cap was used for compression and fixation. After washing the wound with saline, the wound was sutured layer by layer.

\section{Postoperative treatment}

Antibiotics were routinely used for 3 days after operation, and no drainage tube was placed in all the patients. The patients were instructed to exercise moderately on the first 2-3 days after surgery. The two 
groups were given the same adjuvant medication and rehabilitation measures. The follow-up time was 6 months, 12 months, and 24 months after the operation.

\section{Clinical and radiographical evaluation}

The intraoperative blood loss, operation time, average length of stay, and hospitalization expenses were retrieved from the patient's electronic medical records. The data of VAS, ODI score, and intervertebral space height of fusion segment at 6 months, 12 months, and 24 months were collected. The fusion and cage subsidence of each segment at the 24th month of follow-up were recorded.

Disc height: the ventral and dorsal intervertebral space height of the fusion segment was measured on the standing neutral lateral radiographs, and the average value taken. Fusion status: mature trabeculae were observed between the endplate and cage. If the X-ray film was not clear, the lumbar spine CT was used for evaluation [4].

Cage subsidence: this was the difference between the height of intervertebral space within 1 week after operation and that at the 24 months. Mild was defined as the difference $\leq 1 \mathrm{~mm}$, moderate was $1 \mathrm{~mm}$ to $3 \mathrm{~mm}$, and severe was $\geq 3 \mathrm{~mm}[11]$.

Lumbar lateral radiographs with $\geq 1 \mathrm{~mm}$ translucent bands on both sides of the screw were considered as screw loosening.

\section{Statistical analyses}

The Statistical Package for Social Science software was used for data processing (version 20, SPSS Inc., Chicago, IL, USA). The data are expressed as mean \pm standard deviation. Fusion rate, cage subsidence rate, and complication rate are expressed as $\mathrm{n}(\%)$. Student's t-test was used for comparison between groups and within groups. Chi-square test or Fisher's exact test was used for the comparison between rates. $\mathrm{P}<0.05$ was considered statistically significant.

\section{Results}

\section{Demographic data}

There were no significant differences in age, gender, BMI, follow-up time, preoperative diagnosis, fusion segment, comorbidities, and smoking between the two groups (Table 1).

\section{Perioperative conditions}

According to the perioperative conditions, the intraoperative bleeding (148.36 \pm 19.78 in UPS and 232.62 \pm 16.9 in BPS, $p<0.0001$ ), operating time (227.69 \pm 17.69 in UPS and $269.55 \pm 18.74$ in BPS, $p<0.0001)$, and hospitalization expenses ( $\$ 16854.77 \pm 282.08$ in UPS and $21764.41 \pm 331.22$ in BPS, $p<0.0001$ ) of the UPS group were significantly less than those of the BPS group. However, there was no significant difference in average hospital stay between the two groups (Table 2). 


\section{Clinical outcomes}

In terms of clinical efficacy, the VAS and ODI scores of the two groups at each follow-up time point after surgery improved significantly compared with preoperatively, but the VAS-back and ODI scores of the UPS group at 6 months after surgery were lower than in the BPS group $(2.87 \pm 1.03$ vs. $3.38 \pm 1.21 ; p=0.0349$; $22.74 \pm 8.23$ vs. $28.89 \pm 8.93 ; p=0.0019$ ). There was significant no difference between the two groups at the rest of the time (Table 3 ). Complications occurred in both groups, such as pain and numbness in front of the left thigh, segmental vascular injury, iliopsoas/quadriceps weakness, and endplate damage (Figure 2). There was no statistical difference in the incidence of complications between the two groups, including single and overall complications (Table 4).

\section{Radiological outcomes}

In terms of radiological outcomes, the height of the intervertebral space of the fusion segment after the operation in the two groups was significantly higher than before $(p<0.05)$. There was no significant difference between the two groups at each follow-up time point after surgery (Table 5). At the 24 months, the fusion rate of the BPS group was numerically higher than in the UPS group, but there was no significant difference between each segment (Table 6). Moreover, there was no significant difference in the cage subsidence rate of the fusion segment between the two groups at the 24 months (Table 7 ) (Figure 1, 2).

\section{Discussion}

With the aging of the population, the incidence of LDD has also increased significantly . Due to the asymmetric degeneration of the intervertebral disc and facet joints, the lumbar vertebral body has slipped scoliosis, and stenosis pathological changes. Patients often experience intractable low back pain, radicular pain, intermittent claudication, among other symptoms [12]. For LDD with severe symptoms, conservative treatment often fails to achieve satisfactory outcomes, and surgical intervention is required [13]. Posterior lumbar interbody fusion, such as PLIF and TLIF, has been widely used in LDD and good results obtained $[14,15]$. However, the paraspinal muscles need to be stripped for a long time during the operation, resulting in muscle fibrosis after the operation, which may cause intractable low back pain after the operation. Complications, such as cerebrospinal fluid leakage and nerve root injury may also occur during the operation [16]. Since the process of OLIF decompression and fusion are performed through the natural gap between the psoas major muscle and the abdominal aorta, the posterior spinal canal structure is not disturbed, which greatly reduces the incidence of these complications [17]. For LDD that requires single-segment fusion, OLIF stand-alone can be selected, but multilevel disc degeneration needs to be fixed with a posterior pedicle screw. At present, there are still controversies, whether the fixation method should be UPSF or BPSF.

Cappuccion et al. found in the biomechanics of LLIF that BPS is more stable than UPSF, especially in the lateral bending and axial rotation of the spine [18]. Slucky et al. simulated TLIF combined with different pedicle screw fixation on the cadaver, and found that BPSF reduces the lumbar ROM significantly than 
UPSF, but it can provide higher fixation strength in the fused segment [19]. Harris et al. measured the overall and L4-5 ROM on the lumbar spine of the cadaver and found that the reduction in ROM of BPSF compared with UPSF was mainly reflected in the axial rotation and lateral bending [20]. In biomechanics research, we found that BPSF provides higher fixing strength and stability than UPSF, especially in the lateral bending and axial rotation. In theory, although BPSF provides higher fixation strength, it causes the ROM of the fusion segment to be too small, stress shielding, and compensatory increase the ROM and load of the adjacent segments. This causes bone loss in the fused segment and accelerates the degeneration of adjacent segments [21].

In vitro experiments cannot truly reflect the stress state of the lumbar spine under the condition of loadbearing, which requires further clinical evidence. After a follow-up of the clinical cases, some scholars believe that UPSF can provide sufficient fixation strength for a single segment. However, for multiple segments due to insufficient fixation strength, UPSF easily causes cage displacement and is not suitable for multi-segment posterior fixation [22, 4]. Zhang et al. indicated that the clinical efficacy and fusion rate of UPSF is similar to that of BPSF, but with less operation time, blood loss, and hospitalization costs in patients with lumbar spine disease who underwent TLIF combined with posterior fixation treatment [23]. Wen et al. found that OLIF combined with UPSF achieves similar fusion rate and clinical efficacy to that of BPSF in single-segment LDD, and the operation time and hospitalization costs are less [9]. However, the outcomes of OLIF combined with UPS in patients with multilevel LDD have not been investigated. Therefore, we conducted a retrospective study to compare the clinical and radiological outcomes of OLIF combined with UPSF and BPSF in the treatment of multi-level LDD.

In this study, the intraoperative bleeding, operating time, and hospitalization expenses of the UPS group were less than those of the BPS group. This could be because the UPS only exposed the posterior tissue of the lumbar spine on one side and implanted pedicle screws. Intraoperative bleeding was different from the results of Wen et al [9]. It is possible that all cases in this study had not used percutaneous fixation. In OLIF multi-segment surgery, the decompression and fusion process were all performed under "C" arm Xray. If percutaneous pedicle screw fixation was used, radiation exposure time would be increased again, which is a disadvantage to the doctors and patients.

Our study showed that the pain and lumbar function of the two groups were significantly improved at each follow-up time, but at 1 month and 6 months, the outcomes of the UPS group were better than those of the BPS group, and there was no significant difference between the two groups at the last follow-up. These findings were inconsistent with previous results of a meta-analysis [24]. This could be because the meta-analysis included patients who received PLIF, TLIF, and MIS-TLIF. Compared with these surgical methods, OLIF could protect the function of the paraspinal muscles to the most significant extent [25]. The rate of complications between the two groups was not significantly different since the complications were related to the surgical approach of OLIF and were irrelevant to the posterior screw placement process. A total of 33 complications occurred in the two groups of the study, and the total incidence of complications was $40 \%$, which was higher than that reported by previous studies $[26,27]$. We speculate that the all patients included in this study were multi-segment LLD patients, and the psoas major muscle 
was stretched for a long time during the operation [2]; hence, the high incidence of complications. Among them, degenerative lumbar scoliosis accounted for $64 \%$, and patients with L2-5 accounted for $91 \%$, which have been previously documented as factors that increase the incidence of lumbar plexus and segmental vascular injury $[28,29]$.

The radiologic outcomes of this study showed that there was no significant difference in disc height, fusion rate, and cage subsidence between the two groups after surgery. These results were inconsistent with previous findings $[30,22]$. We speculate that this could be closely related to the two surgical decompression mechanisms. OLIF is an indirect decompression, which does not interfere with the vertebral plate and lumbar facet joints during the operation. These tissues belong to the posterior ligament complex (PLC), which is important for maintaining the stability of the spine and affects the fusion rate of the cage [31]. The biomechanical study of Du et al. found that the length of the cage is very important for UPSF to maintain the stability of the spine, which had a small impact on BPSF. It was found that in order to make the UPSF fixation strength of the segment close to that of BPSF, the length of the cage should be higher than the height of the intervertebral space [32]. The cage used for OLIF in this study was a Clydesdale type, and the length was much longer than the intervertebral space height of the fusion segment. Similarly, previous finite element studies have also confirmed that in a single segment, the fixation strength of OLIF combined with UPSF is lower than that of BPSF, but when the lumbar spine moves in all directions, the stress peaks of its cage and pedicle screws are far from reaching their respective levels. Therefore, UPSF could provide sufficient stability [10].

\section{Conclusions}

Overall, in more than 24 months of follow-up, OLIF combined with UPSF has similar clinical effect and segmental stability with BPSF. Compared with BPSF, UPSF has the advantages of short operation time, less intraoperative bleeding, and low hospitalization cost. Therefore, OLIF combined with UPSF is a feasible and effective method for the treatment of multilevel LDD.

\section{Limitations}

Firstly, as prospective single center study, the sample size in this study was relatively small. Secondly, the follow-up time was only about two years, relatively short to evaluate the long-term clinical results of these two different surgical procedures. Therefore, large sample sized studies with a long follow up period are required to provide more reliable clinical research data. Thirdly, this study lacks biomechanical support, and biomechanical research is needed to continue verifying the effect of OLIF combined with UPSF and BPSF on the stability of multi-segment fixation. Finally, some patients in this study were diagnosed with degenerative lumbar scoliosis, and the effect of spinal orthopedic in such patients was not evaluated.

\section{Abbreviations}


UPSF: unilateral pedicle screws fixation; BPSF: bilateral pedicle screws fixation; OLIF: oblique lumbar interbody fusion; TLIF: transforaminal lumbar interbody fusion; PLIF: posterior lumbar interbody fusion; MIS-TLIF: minimally invasive surgery-transforaminal lumbar interbody fusion; BMI: body mass index; ODI: Oswestry Disability Index; VAS: Visual Analog Scale

\section{Declarations}

\section{Ethics approval and consent to participate}

This study was a prospective cohort study and was conducted at the General Hospital of Ningxia Medical University from May 2016 to June 2018. All participants in this study strictly followed the Declaration of Helsinki. The Scientific Research and Ethics Review Committee of the General Hospital of Ningxia Medical University approved this study on April 26, 2019 (NO.2019-038). All participants in this study provided informed consent.

\section{Consent for publication}

Written informed consent for publication was obtained from the patient; each participant was informed that individual details and images would be published in our manuscript.

\section{Availability of data and materials}

The authors declare that all data supporting the findings of this study are available within the article.

\section{Competing interests}

The authors declare that they have no competing interests.

\section{Funding}

This work was supported by grants from the Ningxia Key Research and Development Project ( No.2020BEG03034).

\section{Authors' contributions}

Zecheng Cai and JZ make equal contributions to this study. Zecheng Cai and ZG conceived and designed the experiment. JZ and SY collected the patient samples. $X L$ and Zhen Chen analyzed and interpreted the data. Zecheng Cai prepared the manuscript. RM, SL, and XD reviewed the manuscript. ZM and PW are responsible for the integrity of the data. ZG approved the final version of the manuscript. All authors have read and approved the final submitted manuscript.

\section{Acknowledgements}

We would like to thank all the participants who took part in this research for their time and help.

\section{References}


1. Mobbs RJ, Phan K, Malham G, Seex K, Rao PJ. Lumbar interbody fusion: techniques, indications and comparison of interbody fusion options including PLIF, TLIF, MI-TLIF, OLIF/ATP, LLIF and ALIF. J Spine Surg. 2015;1:2-18. https://doi.org/10.3978/j.issn.2414-469X.2015.10.05.

2. Silvestre C, Mac-Thiong JM, Hilmi R, Roussouly P. Complications and Morbidities of Mini-open Anterior Retroperitoneal Lumbar Interbody Fusion: Oblique Lumbar Interbody Fusion in 179 Patients. Asian Spine J. 2012;6:89-97.https://doi.org/2012;6:89-97.10.4184/asj.2012.6.2.89.

3. Ohtori S, Mannoji C, Orita S, Yamauchi K, Eguchi Y, Ochiai N, Kishida S, Kuniyoshi K, Aoki Y, Nakamura J, Ishikawa T, Miyagi M, Kamoda H, Suzuki M, Kubota G, Sakuma Y, Oikawa Y, Inage K, Sainoh T, Sato J, Shiga Y, Abe K, Fujimoto K, Kanamoto H, Toyone T, Inoue G, Takahashi K. MiniOpen Anterior Retroperitoneal Lumbar Interbody Fusion: Oblique Lateral Interbody Fusion for Degenerated Lumbar Spinal Kyphoscoliosis. Asian Spine J. 2015;9:565-72. https://doi.org/10.4184/asj.2015.9.4.565.

4. Suk KS, Lee HM, Kim NH, Ha JW. Unilateral Versus Bilateral Pedicle Screw Fixation in Lumbar Spinal Fusion. Spine. 2000;25:1843-1847. https://doi.org/10.1097/00007632-200007150-00017.

5. Kabins MB, Weinstein JN, Spratt KF, Found EM, Goel VK, Woody J, Sayre HA. Isolated L4-L5 fusions using the variable screw placement system: unilateral versus bilateral. J Spinal Disord. 1992;5:39-49. https://doi.org/10.1097/00002517-199203000-00006.

6. Yücesoy K, Yüksel KZ, Baek S, Sonntag VK, Crawford NR. Biomechanics of unilateral compared with bilateral lumbar pedicle screw fixation for stabilization of unilateral vertebral disease. J Neurosurg Spine. 2008;8:44-51. https://doi.org/10.3171/SPI-08/01/044.

7. Gu G, Zhang H, Fan G, He S, Meng X, Gu X, Yan N, Guan X. Clinical and radiological outcomes of unilateral versus bilateral instrumentation in two-level degenerative lumbar diseases. Eur Spine $\mathrm{J}$. 2015;24:1640-1648. https://doi.org/10.1007/s00586-015-4031-x.

8. Han YC, Liu ZQ, Wang SJ, Li LJ, Tan J. Comparison of unilateral versus bilateral pedicle screw fixation in degenerative lumbar diseases: a meta-analysis. Eur Spine J. 2014;23:974-984. https://doi.org/10.1007/s00586-014-3221-2.

9. Wen J, Shi C, Yu L, Wang S, Xi Y, Ye X. Unilateral Versus Bilateral Percutaneous Pedicle Screw Fixation in Oblique Lumbar Interbody Fusion. World Neurosurg. 2020; 134: e920-e927. https://doi.org/10.1016/j.wneu.2019.11.035

10. Yin F, Ma R, Cai Z, Yu Y, Yang S, Zhang Y, Chen Z, Ge Z. Three-dimensional finite element analysis of oblique lateral lumbar interbody fusion combined with unilateral pedicle screw fixation. Chin J Spine Spinal Cord. 2019;29:732-740. https://doi.org/10.3969/j.issn.1004-406X.2019.08.09

11. Liu L, Liu G, Zang S, Hong X, Xie X, Wu X, Wang Y. Influence factors analysis of cage subsidence grading after posterior lumbar fusion in osteoporotic patients. Chin J Spine Spinal Cord. 2020;30:111-117. https://doi.org/10.3969/j.issn.1004-406X.2020.02.03.

12. Tribus CB. Degenerative lumbar scoliosis: evaluation and management. J Am Acad Orthop Surg. 2003;11:174-183. https://doi.org/10.3969/j.issn.1004-406X.2020.02.03. 
13. Lee YC, Zotti MG, Osti OL. Operative Management of Lumbar Degenerative Disc Disease. Asian Spine J. 2016;10:801-819. https://doi.org/10.4184/asj.2016.10.4.801.

14. Cole CD, McCall TD, Schmidt MH, Dailey AT. Comparison of low back fusion techniques: transforaminal lumbar interbody fusion (TLIF) or posterior lumbar interbody fusion (PLIF) approaches. Curr Rev Musculoskelet Med. 2009;2:118-26. https://doi.org/10.1007/s12178-009-90538

15. Audat Z, Moutasem O, Yousef K, Mohammad B. Comparison of clinical and radiological results of posterolateral fusion, posterior lumbar interbody fusion and transforaminal lumbar interbody fusion techniques in the treatment of degenerative lumbar spine. Singapore Med J. 2012;53:1837. https://doi.org/10.1007/s00063-012-0094-1

16. Yavin D, Casha S, Wiebe S, Feasby TE, Clark C, Isaacs A, Holroyd-Leduc J, Hurlbert RJ, Quan H, Nataraj A, Sutherland GR, Jette N. Lumbar fusion for degenerative disease: A systematic review and meta-analysis. Neurosurgery. 2017;80:701-715. https://doi.org/10.1093/neuros/nyw162.

17. Phan K, Maharaj M, Assem Y, Mobbs RJ. Review of early clinical results and complications associated with oblique lumbar interbody fusion (OLIF). J Clin Neurosci. 2016;31:23-9. https://doi.org/10.1016/j.jocn.2016.02.030.

18. Cappuccino A, Cornwall GB, Turner AW, Fogel GR, Duong HT, Kim KD, Brodke DS. Biomechanical analysis and review of lateral lumbar fusion constructs. Spine 2010;35(26 Suppl):S361-S367. https://doi.org/10.1097/BRS.0b013e318202308b.

19. Slucky AV, Brodke DS, Bachus KN, Droge JA, Braun JT. Less invasive posterior fixation method following transforaminal lumbar interbody fusion: a biomechanical analysis. Spine J. 2006;6:78-85. https://doi.org/10.1016/j.spinee.2005.08.003.

20. Harris BM, Hilibrand AS, Savas PE, Pellegrino A, Vaccaro AR, Siegler S, Albert TJ. Transforaminal lumbar interbody fusion: the effect of various instrumentation techniques on the flexibility of the lumbar spine. Spine. 2004;29:E65-E70. https://doi.org/10.1097/01.BRS.0000113034.74567.86.

21. Trivedi NN, Wilson SM, Puchi LA, Lebl DR. Evidence-Based analysis of adjacent segment degeneration and disease after LIF: A narrative review. Global Spine J. 2018;8:95-102. https://doi.org/10.1177/2192568217734876/

22. Duncan JW, Bailey RA . An analysis of fusion cage migration in unilateral and bilateral fixation with transforaminal lumbar interbody fusion.Eur Spine J. 2013;22:439-445. https://doi.org/10.1007/s00586-012-2458-x.

23. Zhang K, Sun W, Zhao CQ, Li H, Ding W, Xie YZ, Sun XJ, Zhao J. Unilateral versus bilateral instrumented transforaminal lumbar interbody fusion in two-level degenerative lumbar disorders: a prospective randomised study. Int Orthop. 2014;38:111-116. https://doi.org/10.1007/s00264-0132026-y 
24. Lu P, Pan T, Dai T, Chen G, Shi KQ. Is unilateral pedicle screw fixation superior than bilateral pedicle screw fixation for lumbar degenerative diseases: a meta-analysis. J Orthop Surg Res. 2018;13:296. https://doi.org/10.1186/s13018-018-1004-x

25. Kim DY, Lee SH, Chung SK, Lee HY. Comparison of multifidus muscle atrophy and trunk extension muscle strength: percutaneous versus open pedicle screw fixation. Spine. 2005;30:123-129. https://doi.org/10.1097/01.brs.0000157172.00635.3a

26. Zhang J, Fan S, Fang X, Zhao F, Zhou Z, Zhao X, Hu Z, Liu J, Wang Y. Clinical value of one-level oblique lateral interbody fusion in the treatment of degenerative lumbar disc disease. Chin $\mathrm{J}$ Orthop. 2017;37:80-88. https://doi.org/10.3760/cma.j.issn.0253-2352.2017.02.003

27. Sato J, Ohtori S, Orita S, Yamauchi K, Eguchi Y, Ochiai N, Kuniyoshi K, Aoki Y, Nakamura J, Miyagi M, Suzuki M, Kubota G, Inage K, Sainoh T, Fujimoto K, Shiga Y, Abe K, Kanamoto H, Inoue G, Takahashi $\mathrm{K}$. Radiographic evaluation of indirect decompression of mini-open anterior retroperitoneal lumbar interbody fusion: oblique lateral interbody fusion for degenerated lumbar spondylolisthesis. Eur Spine J. 2017;26:671-678. https://doi.org/10.1007/s00586-015-4170-0

28. Davis TT, Hynes RA, Fung DA, Spann SW, MacMillan M, Kwon B, Liu J, Acosta F, Drochner TE. Retroperitoneal oblique corridor to the L2囚S1 intervertebral discs in the lateral position: an anatomic study. J Neurosurg Spine. 2014;21:785冈793. https://doi.org/10.3171/2014.7.SPINE13564

29. Takata Y, Sakai T, Tezuka F, Yamashita K, Abe M, Higashino K, Ngamachi A, Sairyo K. Risk assessment of lumbar segmental artery injury during lateral transpsoas approach in the patients with lumbar scoliosis. Spine. 2016;41:880-884. https://doi.org/10.1097/BRS.0000000000001362

30. Aoki Y, Yamagata M, Nakajima F, Ikeda Y, Shimizu K, Yoshihara M, Iwasaki J, Toyone T, Nakagawa K, Nakajima A, Takahashi K, Ohtori S. Examining risk factors for posterior migration of fusion cages following transforaminal lumbar interbody fusion: a possible limitation of unilateral pedicle screw fixation. J Neurosurg Spine. 2010;13:381-387. https://doi.org/10.3171/2010.3.SPINE09590

31. Huang YP, Du CF, Cheng CK, Zhong ZC, Chen XW, Wu G, Li ZC, Ye JD, Lin JH, Wang LZ. Preserving posterior complex can prevent adjacent segment disease following posterior lumbar interbody fusion surgeries: A finite element analysis. PLoS ONE. 2016;11:e0166452.

https://doi.org/10.1371/journal.pone.0166452

32. Du L, Sun XJ, Zhou TJ, Li YC, Chen C, Zhao CQ, Zhang K, Zhao J. The role of cage height on the flexibility and load sharing of lumbar spine after lumbar interbody fusion with unilateral and bilateral instrumentation: a biomechanical study. BMC Musculoskeletal Disorders. 2017;18:474. https://doi.org/10.1186/s12891-017-1845-1

\section{Tables}

Table 1. Comparison of demographic data between the two groups 


\begin{tabular}{|llll|}
\hline & UPS group & BPS group & $P$ \\
\hline Mean age (years) & $64.41 \pm 5.78$ & $66.69 \pm 7.18$ & 0.1660 \\
\hline Gender (M/F) & $22 / 17$ & $26 / 16$ & 0.6561 \\
\hline BMI (kg/m $\left.{ }^{2}\right)$ & $23.45 \pm 2.81$ & $24.24 \pm 3.03$ & 0.2280 \\
\hline Mean follow-up time (month) & $26.05 \pm 1.45$ & $26.07 \pm 1.88$ & 0.9573 \\
\hline Preoperative diagnosis & & & 0.6266 \\
\hline Discogenic low back pain & $8(20.51 \%)$ & $7(16.67 \%)$ & \\
\hline Degenerative lumbar spinal stenosis & $8(20.51 \%)$ & $6(14.29 \%)$ & \\
\hline Degenerative lumbar scoliosis & $23(58.94 \%)$ & $29(69.05 \%)$ & \\
\hline The fusion segment & & & 0.7058 \\
\hline
\end{tabular}

\begin{tabular}{|llll|}
\hline L1-4 & $4(10.26 \%)$ & $3(7.14 \%)$ & \\
\hline L2-5 & $35(89.74 \%)$ & $39(92.86 \%)$ & \\
\hline Comorbidities & & & 0.7646 \\
\hline Hypertension & $10(25.64 \%)$ & $9(21.43 \%)$ & \\
\hline Diabetes & $4(10.26 \%)$ & $6(14.29 \%)$ & \\
\hline Coronary heart disease & $2(5.13 \%)$ & $3(7.14 \%)$ & \\
\hline Smoking history & $13(33.33 \%)$ & $15(35.71 \%)$ & $>0.9999$ \\
\hline
\end{tabular}

Table 2. Comparison of surgical outcomes between the two groups

\begin{tabular}{|llll|}
\hline & UPS group & BPS group & $P$ \\
\hline Intraoperative bleeding (ml) & $148.36 \pm 19.78$ & $232.62 \pm 16.9$ & $<0.0001$ \\
\hline Operating time (min) & $227.69 \pm 17.69$ & $269.55 \pm 18.74$ & $<0.0001$ \\
\hline Average hospital stay (day) & $13.44 \pm 1.59$ & $12.98 \pm 1.09$ & 0.1363 \\
\hline Hospitalization expenses (\$) & $16854.77 \pm 282.08$ & $21764.41 \pm 331.22$ & $<0.0001$ \\
\hline
\end{tabular}


Table 3. VAS and ODI scores before and after surgery in the two groups

\begin{tabular}{|llllll|}
\hline \multicolumn{1}{|c}{} & Pre-op & $\begin{array}{l}6 \text { months post- } \\
\text { op }\end{array}$ & $\begin{array}{l}12 \text { months post- } \\
\text { op }\end{array}$ & $\begin{array}{l}24 \text { months post- } \\
\text { op }\end{array}$ \\
\hline $\begin{array}{l}\text { VAS- } \\
\text { back }\end{array}$ & $\begin{array}{l}\text { UPS } \\
\text { group }\end{array}$ & $6.69 \pm 1.06$ & $2.87 \pm 1.03$ & $2.31 \pm 1.20$ & $2.26 \pm 1.19$ \\
& $\begin{array}{l}\text { BPS } \\
\text { group }\end{array}$ & $6.50 \pm 0.99$ & $3.38 \pm 1.21$ & $2.64 \pm 1.06$ & $2.33 \pm 1.18$ \\
\hline VAS-leg & $\begin{array}{l}\text { UPS } \\
\text { group }\end{array}$ & $6.82 \pm 0.72$ & $3.03 \pm 0.74$ & $2.33 \pm 1.03$ & $2.23 \pm 1.06$ \\
& $\begin{array}{l}\text { BPS } \\
\text { group }\end{array}$ & $6.57 \pm 1.02$ & $3.10 \pm 0.96$ & $2.43 \pm 0.97$ & $2.26 \pm 1.17$ \\
\hline ODI & $\begin{array}{l}\text { UPS } \\
\text { group }\end{array}$ & $52.93 \pm 8.04$ & $22.74 \pm 8.23$ & $14.64 \pm 3.00$ & $14.42 \pm 3.67$ \\
& $\begin{array}{l}\text { BPS } \\
\text { group }\end{array}$ & $50.53 \pm$ & $28.89 \pm 8.93$ & $15.4 \pm 4.06$ & $15.24 \pm 3.56$ \\
\hline
\end{tabular}

Table 4. Comparison of complications between the two groups

\begin{tabular}{|llll|}
\hline & UPS & BPS & $P$ \\
\hline Pain and numbness in front of left thigh & $6(15.38 \%)$ & $7(16.67 \%)$ & $>0.9999$ \\
\hline Segmental vascular injury & $4(10.26 \%)$ & $3(9.52 \%)$ & 0.7058 \\
\hline Iliopsoas/quadriceps weakness & $3(7.69 \%)$ & $4(9.52 \%)$ & $>0.9999$ \\
\hline Endplate damaged & $4(10.26 \%)$ & $2(4.76 \%)$ & 0.4212 \\
\hline Total & $17(43.59 \%)$ & $16(38.10 \%)$ & 0.6561 \\
\hline
\end{tabular}

Table 5. Comparison of disc height between two groups of patients with fusion segment 


\begin{tabular}{|clllll|}
\hline \multirow{2}{*}{ L1-2 } & & pre-op & 6 months post-op & 12 months post-op & 24 months post-op \\
\cline { 2 - 6 } & $4.53 \pm 1.47$ & $8.88 \pm 0.51$ & $8.65 \pm 0.54$ & $8.24 \pm 0.66$ \\
\hline \multirow{2}{*}{ L2-3 } & UPS & $4.38 \pm 1.26$ & $9.18 \pm 0.72$ & $9.04 \pm 0.75$ & $8.91 \pm 0.86$ \\
\cline { 2 - 6 } & BPS & $5.23 \pm 0.88$ & $9.76 \pm 1.21$ & $8.63 \pm 1.28$ & $8.40 \pm 1.25$ \\
\hline L3-4 & UPS & $6.54 \pm 0.75$ & $11.01 \pm 1.07$ & $10.07 \pm 1.15$ & $9.88 \pm 1.16$ \\
\cline { 2 - 6 } & BPS & $6.42 \pm 1.40$ & $10.91 \pm 1.69$ & $10.25 \pm 1.85$ & $10.07 \pm 1.84$ \\
\hline \multirow{2}{*}{ L-5 } & UPS & $8.47 \pm 0.90$ & $12.99 \pm 1.28$ & $12.19 \pm 1.28$ & $11.99 \pm 1.16$ \\
\cline { 2 - 6 } & BPS & $8.55 \pm 0.83$ & $13.11 \pm 1.33$ & $12.42 \pm 1.48$ & $12.23 \pm 1.47$ \\
\hline
\end{tabular}

Table 6. Comparison of fusion rates between the two groups at the 24th month after surgery

\begin{tabular}{|llll|}
\hline Segment & UPS (\%) & BPS (\%) & $P$ \\
\hline L1-2 & $100(4 / 4)$ & $100(3 / 3)$ & $>0.9999$ \\
\hline L2-3 & $92.30(36 / 39)$ & $95.24(40 / 42)$ & 0.6608 \\
\hline L3-4 & $89.74(35 / 39)$ & $95.24(40 / 42)$ & 0.4212 \\
\hline L4-5 & $88.57(31 / 35)$ & $92.31(36 / 39)$ & 0.7009 \\
\hline
\end{tabular}

Table 7 Comparison of the cage subsidence level of the two groups at the 24th month after surgery 


\begin{tabular}{|c|c|c|c|c|c|}
\hline & & \multicolumn{3}{|c|}{ Level of subsidence } & \multirow[t]{2}{*}{$P$ value } \\
\hline & & mild (\%) & moderate (\%) & severe (\%) & \\
\hline \multirow[t]{2}{*}{ L1-2 } & UPS & $75.00(3 / 4)$ & $25.00(1 / 4)$ & 0 & \multirow[t]{2}{*}{$>0.9999$} \\
\hline & BPS & $100.00(3 / 3)$ & 0 & 0 & \\
\hline \multirow[t]{2}{*}{ L2-3 } & UPS & $82.05(32 / 39)$ & $10.26(4 / 39)$ & $7.69(3 / 39)$ & \multirow[t]{2}{*}{0.4611} \\
\hline & BPS & $90.48(38 / 42)$ & $7.14(3 / 42)$ & $2.38(1 / 42)$ & \\
\hline \multirow[t]{2}{*}{ L3-4 } & UPS & $82.08(32 / 39)$ & $15.38(6 / 39)$ & $7.69(3 / 39)$ & \multirow[t]{2}{*}{0.8133} \\
\hline & BPS & $83.33(35 / 42)$ & $11.90(5 / 42)$ & $4.76(2 / 42)$ & \\
\hline \multirow[t]{2}{*}{ L4-5 } & UPS & $77.14(27 / 35)$ & $14.29(5 / 35)$ & $8.57(3 / 35)$ & \multirow[t]{2}{*}{0.7058} \\
\hline & BPS & $84.62(33 / 39)$ & $10.26(4 / 39)$ & $5.13(2 / 39)$ & \\
\hline
\end{tabular}

Figures
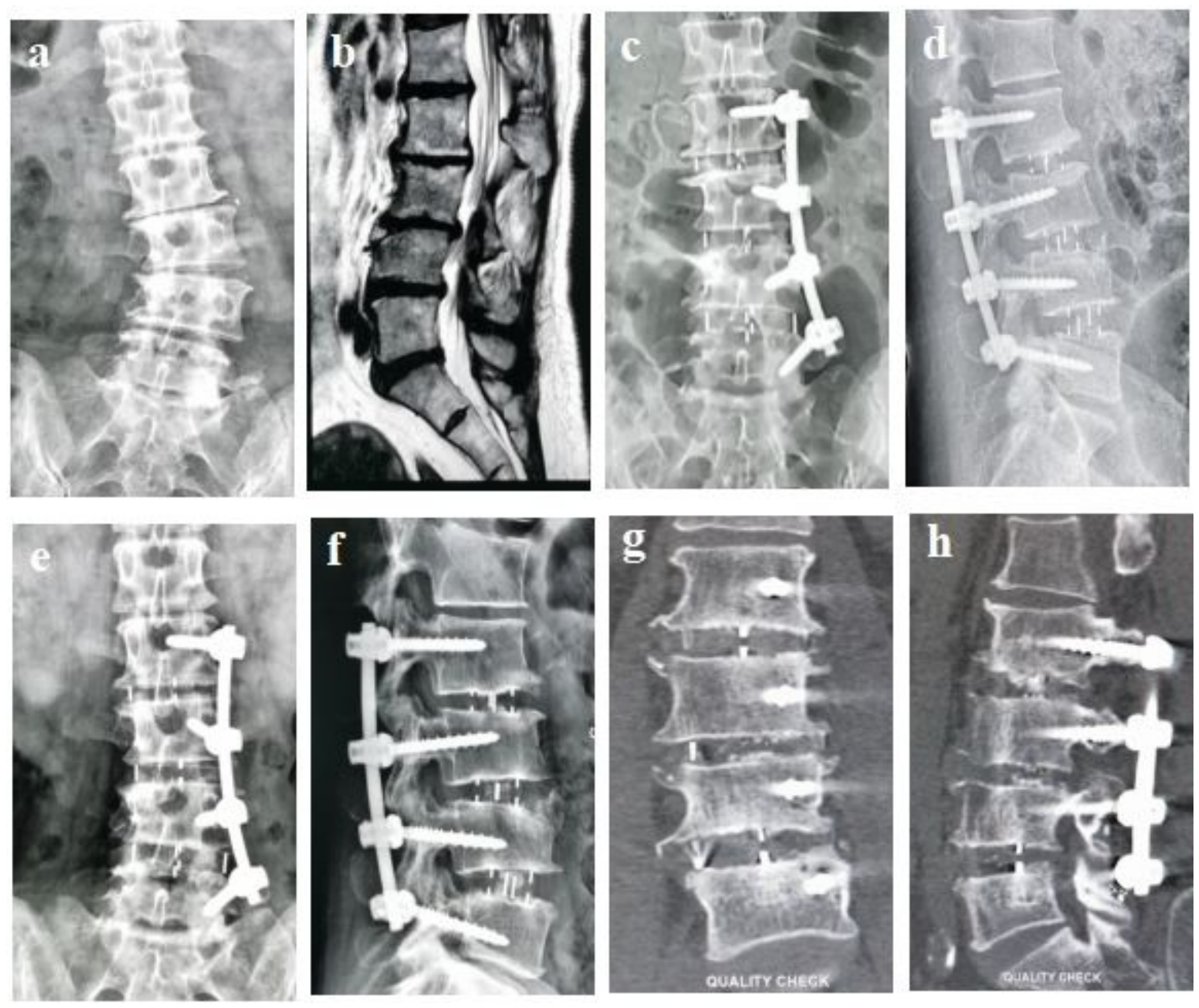

Figure 1 
Case 1: A 68 year old man with low back pain accompanied with numbness of right lower limb for 1 year and aggravating for 3 months, underwent OLIF combine with UPSF. $a, b$ Preoperative lumbar anteroposterior radiographs showed L2-L5 degenerative scoliosis, and MRI showed multilevel lumbar disc herniation. c, d Compared with preoperatively, the patient's symptoms were significantly reduced immediately after surgery. Lumbar radiographs showed that the cage was in good position, the height of the intervertebral space increased significantly, and the unilateral pedicle screw was fixed in place. e, $f 6$ months after surgery, lumbar radiographs showed that the cage and UPSF were fixed in place. $\mathrm{g}, \mathrm{h}$ Computed Tomography (CT) at 24 months after surgery showed that all the surgical segments achieved bony fusion.
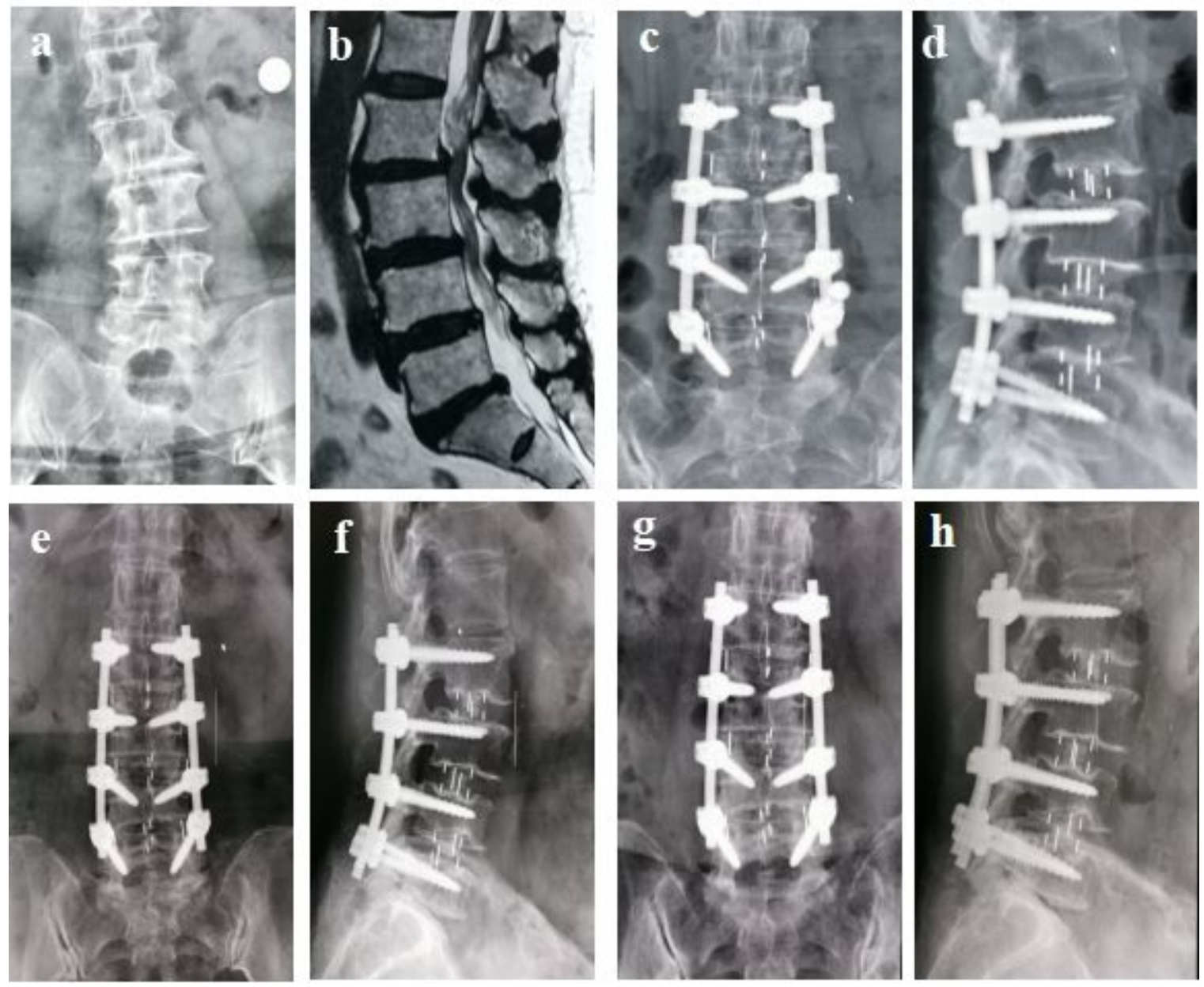

Figure 2

Case 2: A female, 72 years old, with low back pain and intermittent claudication for 1 year, underwent OLIF combine with BPSF. a, b The preoperative lumbar anterior radiograph showed degenerative scoliosis of L2-5 lumbar spine, and MRI showed multi-segment lumbar disc herniation. c, d Immediately after operation, anteroposterior radiographs showed that the endplate of L1-2 was slightly collapsed, the height of the intervertebral space in each segment increased significantly, and the BPSF was fixed in place. e, f 12 months after operation, CT showed cage and BPSF fixed in place. g, h 24 months after the operation, all the surgical segments achieved bony fusion and the cage had slight subsidence, but the patient did not complain of symptoms such as low back pain. 